\title{
Antinociceptive effect of intrathecal neostigmine evaluated in rats by two different pain models
}

W.A. Prado and

A.S. Gonçalves
Departamento de Farmacologia, Faculdade de Medicina de Ribeirão Preto, Universidade de São Paulo, Ribeirão Preto, SP, Brasil

\section{Correspondence \\ W.A. Prado \\ Departamento de Farmacologia \\ Faculdade de Medicina de \\ Ribeirão Preto \\ 14049-900 Ribeirão Preto, SP Brasil \\ E-mail: wadprado@fmrp.usp.br}

Research supported by FAPESP. A.S. Gonçalves was the recipient of a FAPESP fellowship (No. 95/9402-4).

Received June 4, 1997

Accepted August 25, 1997

\begin{abstract}
The analgesic efficacy of cholinergic agonists and anticholinesterase agents has been widely recognized. The analgesic effect obtained by activating cholinergic mechanisms, however, seems to depend on the experimental pain model utilized for its evaluation. The antinociceptive effect of intraspinal neostigmine was examined in rats submitted concurrently to the tail flick and formalin tests. Neostigmine (8.25 and $16.5 \mathrm{nmol}$ ) produced a dose-dependent antinociceptive effect in the tail flick test (a model of phasic pain) and reduced the first phase (phasic pain) of the animal response to formalin also in a dosedependent manner. The second phase (tonic pain) of the response to formalin, however, was slightly reduced after a longer period of time only by the higher dose of the anticholinesterase. The effect of neostigmine was not significantly different when the drug was injected into rats submitted exclusively to the tail flick test. The second phase of the animal response to formalin was slightly reduced by neostigmine $(8.25 \mathrm{nmol})$ and strongly inhibited by the higher dose of the anticholinesterase when injection was made after the first phase. We conclude that phasic and tonic pain can both be controlled by high doses of neostigmine. In addition, we show that inhibition by a lower dose of neostigmine of the formalin-induced phasic pain did not prevent the subsequent occurrence of tonic pain produced by the irritant.
\end{abstract}

\section{Introduction}

The antinociceptive effects of cholinergic agonists and anticholinesterase agents have been demonstrated in several animal species (see Ref. 1). At least in rats (2-5) and cats (2), cholinergic antinociception seems to be mediated by spinal muscarinic receptors. The intrinsic mechanism involved in cholinergic antinociception is not known, but there is evidence for the existence of spinal cholinergic
Key words

- Antinociception

- Neostigmine

- Cholinergic antinociception systems that may act to inhibit the release of neurotransmitters from sensory neurons. Acetylcholine (6), cholinacetyltransferase $(7,8)$, and acetylcholinesterase (9) were identified in both dorsal and ventral portions of the spinal cord. Muscarinic receptors were identified in both laminae II and III of the spinal dorsal horn $(10,11)$. On the other hand, histochemical studies did not identify supraspinal cholinergic neurons projecting to the spinal cord (12), thus indicating that cholinergic terminals in the 
spinal dorsal horn are associated with local neuronal systems.

Neostigmine is a potent anticholinesterase agent known to produce antinociception in the rat following intraventricular administration (13). The intraspinal administration of neostigmine produces long-lasting analgesia in laboratory animals (1) and volunteers $(14,15)$, and permits the management of both postoperative (16) and cancer pain (17). The antinociceptive effect of manipulating the central cholinergic system, however, seems to depend on the animal species and/or algesimetric assay utilized (see Ref. 1). Intraspinal neostigmine effectively controls vaginal and abdominal incision pain, but not visceral pain, in patients submitted to laparotomy for tubal ligation and vaginoplasty (18). Therefore, it is possible that somatic but not visceral pain can be adequately controlled by medullary cholinergic mechanisms.

Therefore, in the present study we examined the antinociceptive effects of intraspinal neostigmine on rats submitted to the tail flick and formalin tests. The tail flick test involves a medullary reflex response to shortlasting phasic pain (19), while the formalin test is characterized by short-lasting phasic pain followed by long-lasting tonic pain involving peripheral and medullary mechanisms of sensitization $(20,21)$. We demonstrate here that intraspinal neostigmine effectively inhibits the animal response to phasic pain in both tests but only slightly reduces the response to tonic pain in the formalin test.

\section{Material and Methods}

\section{Subjects and surgery}

The experiments were carried out on male Wistar rats (250-300 g) housed two to a cage with free access to food and water and maintained at an average room temperature of $22^{\circ} \mathrm{C}$ on a 12 -h light-dark cycle before and after surgery. The proposals of the Committee for Research and Ethical Issue of IASP (22) were followed throughout the experiments. Each animal was anesthetized with sodium thiopentone $(50 \mathrm{mg} / \mathrm{kg}$, ip) and an intrathecal (it) catheter was implanted using a method described elsewhere (23). The catheter was a polyethylene tube $(9 \mathrm{~cm}$ long, OD $=0.4 \mathrm{~mm}$, dead-space $=8.5 \mu \mathrm{l})$ inserted through the dura overlying the atlanto-occipital junction into the subarachnoid space, until the tip lay in the lumbo-sacral region. A 20-mm length of a 23-gauge stainless steel tube was introduced into the free tip of the catheter, and the assembly was fixed to the skull with 3 steel screws and dental cement. At the end of these procedures, penicillin (50 $\mathrm{mg} / \mathrm{kg}, \mathrm{im}$ ) was administered and the animal was allowed to recover for at least one week before the experiments. Animals exhibiting motor abnormalities during the postoperative resting period were not used in these studies.

\section{Tail flick test}

The animal was placed in a glass tube for about $15 \mathrm{~s}$, with the tail lying across a nichrome wire coil which was heated by the passage of electric current. The coil temperature was increased from room temperature (average room temperature $=23^{\circ} \mathrm{C}$ ), and the electric current adjusted to ensure tail flick latencies of 2.5 to $3.5 \mathrm{~s}$. A cut-off time of $6 \mathrm{~s}$ was used to reduce the probability of skin damage. Animals were tested every $10 \mathrm{~min}$ until a stable baseline was obtained in 3 consecutive trials, and then for up to $60 \mathrm{~min}$ following it injection of drug or saline at 10 min intervals. Animals were discarded whenever baseline was not reached in 6 consecutive trials. Each tail flick latency (TL) was normalized using an index of antinociception (IA) according to the formula IA $=(\mathrm{TL}$ - ABL $) /(6-\mathrm{ABL})$, where $\mathrm{ABL}$ is the mean of 3 consecutive latencies obtained before it administration. 


\section{Formalin test}

Formalin $(5 \%, 50 \mu \mathrm{l})$ was injected subcutaneously into the plantar surface of the right hind paw. The animal was then placed inside an acrylic-walled cylinder measuring $50 \mathrm{~cm}$ in diameter and $40 \mathrm{~cm}$ in height with a mirror positioned on the opposite side to allow unhindered observation of the formalin-injected paw, and the behavioral changes were continuously recorded with a videocamera. The sum of the time spent licking plus elevating the injected paw from the cylinder floor (pain intensity score) was determined at 2-min intervals throughout the first 10-min period after formalin administration, and then for up to $60 \mathrm{~min}$ at $10-\mathrm{min}$ intervals.

\section{Intrathecal injection and examination of the catheter position}

A polyethylene tube filled with drug-free saline or saline containing neostigmine was used for $i t$ administration. A small air bubble was retained within the liquid column in the catheter. A shift of $10 \mathrm{~cm}$ in the bubble position corresponded to a volume of 8.33 $\mu \mathrm{l}$, which was taken as the volume of injection throughout the experiments. After injection of saline or neostigmine the catheter was flushed with a further injection of 8.33 $\mu \mathrm{l}$ of drug-free saline.

At the end of the experiment, Fast green $(2 \mu \mathrm{l})$ was injected $i t$ to label the site of injection. Only rats whose injection site was on the dorsomedial or dorsolateral side of the spinal cord were considered for further analysis.

\section{Data analysis}

The results obtained with the tail flick test are reported as graphs of averaged index of antinociception against time of readings. Graphs of averaged time of paw elevation against time of readings were used for the formalin test analysis. Statistical analysis was done using MANOVA with repeated measures to compare the experimental groups over the time. The factors analyzed were treatments, time and treatment $x$ time interaction. In the case of significant treatment $x$ time interactions one-way ANOVA followed by the Duncan test was performed at each time. The analysis was performed with the software package SPSS/PC+, version 3.0, and the level of significance was set at $\mathrm{P}<0.05$.

\section{Drug}

The drug used was neostigmine bromide (Sigma Chemical Co., St. Louis, MO) diluted in saline. Doses used in the tests are referred to as salt.

\section{Results}

\section{Effect of neostigmine administered before formalin}

In this set of experiments the animal was initially submitted to the tail flick test for recording of baseline tail flick latencies. Neostigmine was injected intrathecally and formalin was then injected subcutaneously. The animal was then placed inside the acrylicwalled cylinder from where it was taken at 10-min intervals to allow tail flick latency recording. A period of up to $30 \mathrm{~s}$ elapsed between the two drug administrations.

The intrathecal administration of neostigmine (8.25 and $16.5 \mathrm{nmol}$ ) produced a dose-dependent antinociception in the tail flick test (Figure 1). The curves in Figure 1 were significantly different regarding treatments $\left(F_{2,17}=16.88 ; \mathrm{P}<0.001\right)$. The effect of the higher dose of neostigmine was significantly different from control during all times from 0 to $50 \mathrm{~min}$.

Rats treated with intrathecal saline (8.33 $\mu \mathrm{l})$ followed by subcutaneous formalin showed a biphasic change of the algesimetric 
index, i.e., a period of phasic pain (0-10 min) followed by a period of tonic pain (10-60 $\mathrm{min})$ that was similar to that previously reported $(24,25)$. Intrathecal neostigmine produced a dose-dependent inhibition of the animal response to formalin (Figure 2). MANOVA applied to the curves in the first phase of the response to formalin revealed significant differences between the 3 treatments $\left(\mathrm{F}_{2,17}=7.75 ; \mathrm{P}=0.004\right)$ and significant treatment $\mathrm{x}$ time interactions $\left(\mathrm{F}_{8,68}=\right.$ $2.2 ; \mathrm{P}=0.038$ ). The effect of the higher dose of neostigmine was significantly different from the other treatments at time $4 \mathrm{~min}$, and

Figure 1 - Time course of the effects of intraspinal neostigmine (NEOST) in the rat tail flick test. All animals received intraplantar formalin $(5 \%, 50 \mu l) 30 \mathrm{~s}$ after neostigmine. Neostigmine was injected at the time indicated by the arrow. Data are reported as means \pm SD for 6 or 7 animals per group. ${ }^{*} P<0.05$ compared to control (saline) (Duncan test).
Figure 2 - Time course of the effects of intraspinal neostigmine (NEOST) in the rat formalin test. Neostigmine was injected at the time indicated by arrow 1 . Intraplantar formalin (5\%, $50 \mu \mathrm{l})$ was administered at the time indicated by arrow 2. Data are reported as means \pm SD for 6 or 7 animals per group. ${ }^{*} \mathrm{P}<0.05$ compared to control (saline): $+P<0.05$ compared to control and $8.25 \mathrm{nmol}$ NEOST (Duncan test).
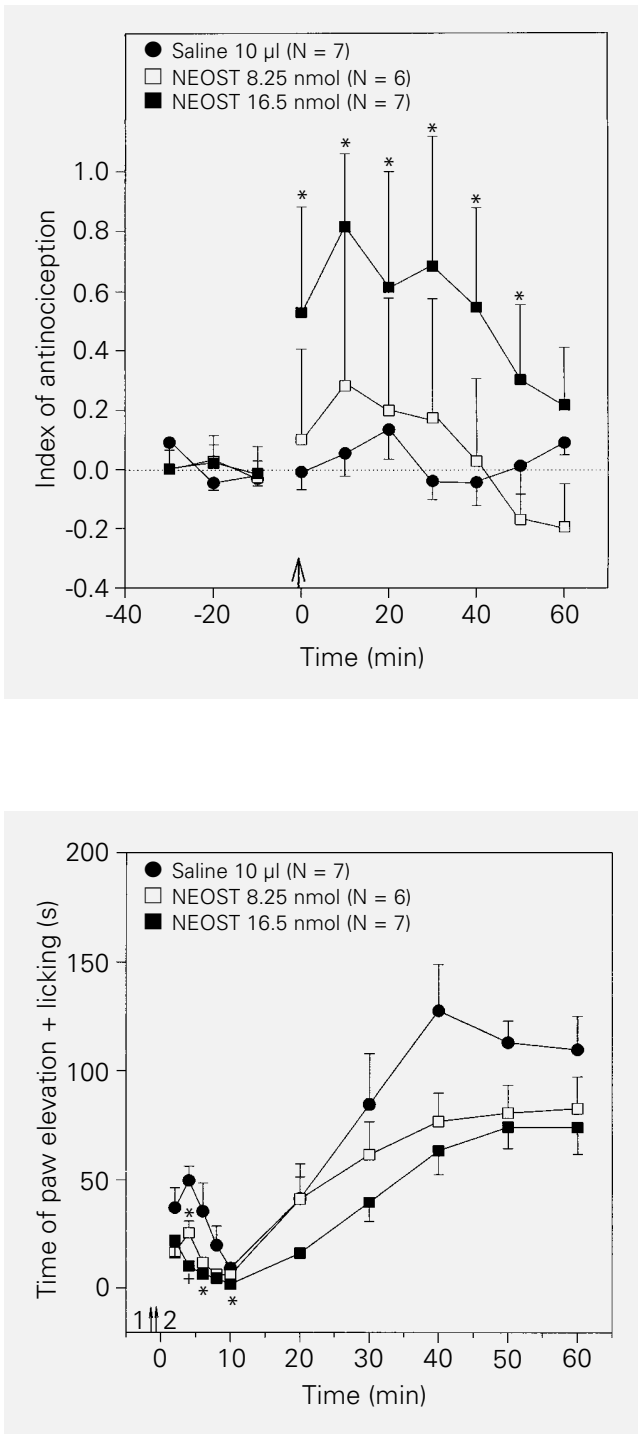

different from control at times 6 and $10 \mathrm{~min}$. The smaller dose produced an effect different from control at 4 min only (ANOVA followed by the Duncan test). MANOVA applied to the curves in the second phase of the response to formalin showed significant differences between the 3 treatments $\left(\mathrm{F}_{2,17}=\right.$ 4.40; $\mathrm{P}=0.029)$, but the treatment $\mathrm{x}$ time interactions were nonsignificant $\left(\mathrm{F}_{10,85}=\right.$ $1.34 ; \mathrm{P}=0.22$ ).

\section{Effect of neostigmine on the tail flick test in the absence of formalin}

Neostigmine (8.25 and $16.5 \mathrm{nmol}$, it) also produced a dose-dependent antinociception in rats not treated with formalin (Figure 3). The curves in Figure 3 were significantly different regarding treatments $\left(\mathrm{F}_{2,13}=11.78 ; \mathrm{P}=0.001\right)$ and treatment $\mathrm{x}$ time interactions $\left(\mathrm{F}_{18,117}=3.37 ; \mathrm{P}<0.001\right)$. The effect of the higher dose of neostigmine was significantly different from the effect of the other treatments at times 0 to $30 \mathrm{~min}$, and different from control at times 40 and 50 $\min$. The smaller dose produced effects different from control at times 0,20 and $40 \mathrm{~min}$.

The control curves in Figures 1 and 3 were not significantly different $\left(\mathrm{F}_{1,11}=1.92\right.$; $\mathrm{P}=0.194)$ and did not show significant treatment $x$ time interactions $\left(\mathrm{F}_{9,99}=1.87 ; \mathrm{P}\right.$ $=0.065)$. The curves obtained with the higher dose of neostigmine in the presence and absence of formalin were also not significantly different $\left(\mathrm{F}_{1,10}=1.79 ; \mathrm{P}=0.211\right)$ but showed significant treatment $x$ time interaction $\left(\mathrm{F}_{9,90}=2.18 ; \mathrm{P}=0.031\right)$. The effect of neostigmine in the absence of formalin was significantly stronger than in the presence of formalin at time $\mathrm{t}=0$ only $\left(\mathrm{F}_{1,11}=8.78 ; \mathrm{P}=\right.$ 0.0142 ). The effects of the smaller dose of neostigmine were significantly less intense in formalin-treated rats $\left(\mathrm{F}_{1,9}=7.24 ; \mathrm{P}=\right.$ $0.025)$. Significant treatment $x$ time interactions were observed for the two curves $\left(\mathrm{F}_{9,81}\right.$ $=2.57 ; \mathrm{P}=0.012$ ) and the effects were significantly different at times 0 and $50 \mathrm{~min}$. 
Effect of neostigmine administered after the first phase of the response to formalin

The intrathecal administration of neostigmine ( 8.25 and $16.5 \mathrm{nmol}) 10 \mathrm{~min}$ after the subcutaneous administration of formalin significantly reduced the second phase of the response to formalin (Figure 4). The curves were significantly different regarding treatments $\left(\mathrm{F}_{2,16}=12.89 ; \mathrm{P}<0.001\right)$ and showed significant treatment $x$ time interactions $\left(\mathrm{F}_{8,64}=2.12 ; \mathrm{P}=0.046\right)$. The effect of the smaller dose of neostigmine was significantly different from control at times 40 to $60 \mathrm{~min}$, while the higher dose of neostigmine completely abolished the response to formalin.

When the data in Figures 2 and 4 were compared, no significant difference was detected between the effects of neostigmine $(8.25 \mathrm{nmol})$ in the second phase of the response to formalin, injected before or $10 \mathrm{~min}$ after this irritant. The curves did not differ regarding treatments $\left(\mathrm{F}_{1,10}=1.79 ; \mathrm{P}=0.21\right)$ nor did they show significant treatment $\mathrm{x}$ time interactions $\left(\mathrm{F}_{4,40}=1.15 ; \mathrm{P}=0.348\right)$. Different results were obtained with the higher dose of neostigmine. The curves were significantly different regarding treatments $\left(\mathrm{F}_{1,11}=7.35 ; \mathrm{P}=0.02\right)$ and showed significant treatment $\mathrm{x}$ time interactions $\left(\mathrm{F}_{4,44}=\right.$ 5.33; $\mathrm{P}=0.001$ ). However, significant differences were found at times $\mathrm{t}=50$ and 60 min only. When the pain intensity score during the $40 \mathrm{~min}$ of observation of the second phase of the response to formalin was summed, a significant difference was also found only between the groups treated with the higher dose of neostigmine (Figure 5).

\section{Discussion}

The present results using two different pain models confirm that intraspinal neostigmine produces a dose-dependent antinociceptive effect in rats. The peak effect of intraspinal neostigmine was higher and oc-

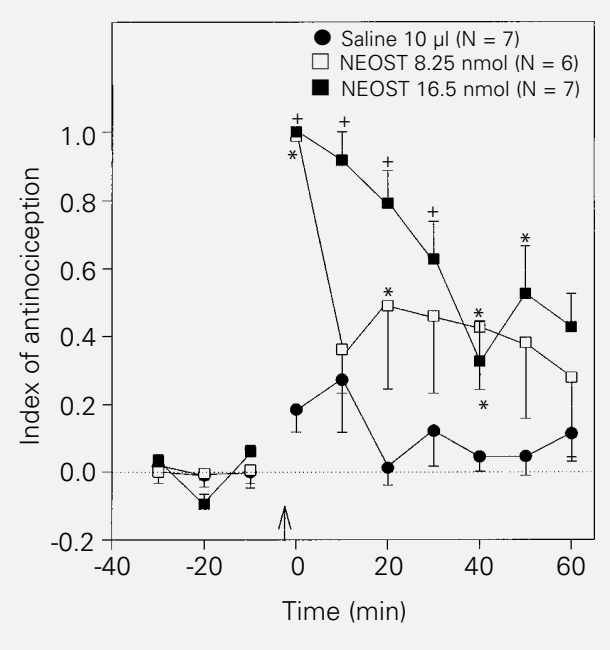

Figure 3 - Time course of the effects of intraspinal neostigmine (NEOST) in the rat tail flick test. Neostigmine was injected at the time indicated by the arrow. Data are reported as means \pm SD for 6 or 7 animals per group. ${ }^{*} \mathrm{P}<0.05$ compared to control (saline); $+P<0.05 \mathrm{com}$ pared to control and $8.25 \mathrm{nmol}$ NEOST (Duncan test).

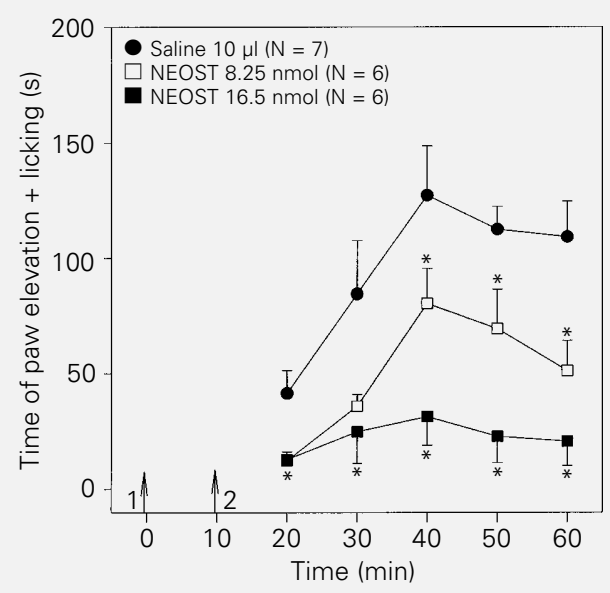

Figure 4 - Time course of the effects of intraspinal neostigmine (NEOST) on the second phase of the response of rats to intraplantar administration of formalin $(5 \%, 50 \mu \mathrm{l})$. Neostigmine and formalin were injected at the times indicated by arrows 1 and 2, respectively. Data are reported as means \pm SD for 6 or 7 rats per group. ${ }^{*} \mathrm{P}<0.05 \mathrm{com}$ pared to control (saline) (Duncan test).

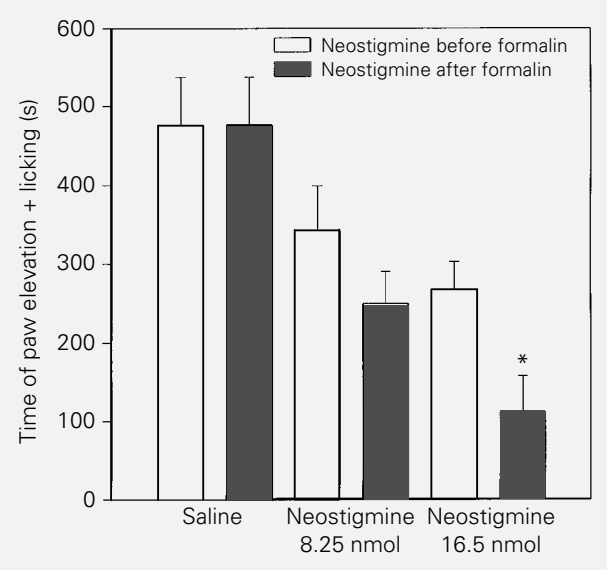

Figure 5 - Comparative effects of intraspinal neostigmine administered to rats $30 \mathrm{~s}$ before or 10 min after intraplantar injection of formalin $(5 \%, 50 \mu l)$ on the total time of paw elevation plus licking. Bars represent the means $\pm S D$ of 6 or 7 rats per group. ${ }^{*} \mathrm{P}<0.05$ compared to the group pre-treated with neostigmine (unpaired $t$-test). 
curred earlier in animals submitted exclusively to the tail flick test than in animals concurrently submitted to the formalin test. The effects obtained in these experiments, however, were significantly different only at times 0 and $50 \mathrm{~min}$. The threshold for the tail withdrawal reflex to noxious heating of the skin was demonstrated to be significantly reduced during the tonic phase of the response to intraplantar formalin (26). Thus, in the case of concomitant application of both tests, hyperalgesia in the tail skin would be expected to require a higher dose of neostigmine to obtain a clear antinociceptive effect. However, the control curves obtained under the two experimental conditions did not differ significantly. Therefore, the formalin-induced hyperalgesia in the tail skin was not demonstrated under our experimental conditions.

Previous administration of neostigmine significantly inhibited the first phase of the response to formalin but produced only a slight reduction of the second phase which was significantly different from the control only at later readings. The administration of neostigmine subsequent to the first phase of the response to formalin also reduced the tonic pain in a dose-dependent manner. In this case, the higher dose of neostigmine was fully effective throughout the period of observation while the smaller dose was effective only at the later readings. Comparison of the curves obtained in the two experimental situations revealed significant differences only for the curves obtained with the smaller dose of neostigmine.

Behavioral $(24,25)$ and electrophysiological studies (27) have shown that previous administration of morphine or the $\mu$-opioid agonist DAMGO inhibits both components of the response to formalin. The effectiveness of DAMGO, however, is significantly lower when it is administered after the completion of the phasic component (27). Physiological and pharmacological studies have indicated that the two phases of the response to formalin are different. The spinal control of phasic noxious inputs utilizes descending mechanisms which are different from those that control tonic noxious inputs (28). Intrathecal injection of NMDA, AMPA, and NK-1 antagonists has little influence on the first phase but all eliminate or strongly reduce the second phase reactions to formalin (29-31). The neurotransmitter involved in each type of pain also seems to be different (32). Substance P seems to be responsible for the nociceptive inputs originated by transitory stimuli as in the case of the tail flick reflex and in the first component of the response to formalin. Excitatory amino acids such as glutamate and somatostatin seem to be responsible for the spinal entry of longlasting noxious inputs, as observed in the second phase of the response to formalin or during inflammatory processes (33).

In our experiments, the neostigmine-induced inhibition of the first component of the response to formalin reduced but did not prevent the occurrence of tonic pain. The neostigmine-induced inhibition of the tail withdrawal reflex confirms its effectiveness against phasic pain. In addition, the results resemble the clinical observation that neostigmine is effective against somatic postoperative pain but is less useful to control visceral postoperative pain in human beings (18). The observation that the higher dose of neostigmine is fully effective when administered after formalin, however, suggests that the use of a high intraspinal dose of neostigmine would be an alternative to improve its effectiveness in the management of postoperative pain. Attempts to increase the dosage of intraspinal neostigmine, however, have resulted in higher incidence of nausea, vomiting and defecation $(18,34)$ which limit its clinical usefulness.

\section{Acknowledgments}

We thank Mr. P.R. Castania for technical assistance. 


\section{References}

1. Green PG \& Kitchen I (1986). Antinociception opioids and the cholinergic system. Progress in Neurobiology, 26: 119-146.

2. Yaksh TL, Dirksen R \& Harty GJ (1985). Antinociceptive effects of intrathecally injected cholinomimetic drugs in the rat and cat. European Journal of Pharmacology, 117: 81-88.

3. Gillberg PG, Gordh Jr T, Hartvig P, Pettersson J \& Post C (1989). Characterisation of the antinociception induced by intrathecally administered carbachol. Pharmacology and Toxicology, 64: 340343.

4. Smith MD, Nha JY \& Buccafusco JJ (1989). Antinociceptive effects of spinal cholinergic stimulation: interaction with substance P. Life Sciences, 45: 12551261.

5. Zhuo M \& Gebhart GF (1991). Tonic cholinergic inhibition of spinal mechanical transmission. Pain, 46: 211-222.

6. McIntosh FC (1941). The distribution of acetylcholine in the peripheral and the central nervous system. Journal of Physiology, 99: 436-442.

7. Feldberg W \& Vogt M (1948). Acetylcholine synthesis in different regions of the central nervous system. Journal of Physiology, 107: 372-381.

8. Kasa P, Mann SP \& Hebb CO (1970). Localization of cholinacetyltransferase. Nature, 226: 812-816.

9. Roessmann U \& Friede RL (1967). The segmental distribution of acetylcholinesterase in the cat spinal cord. Journal of Anatomy, 101: 27-32.

10. Gillberg PG, d'Argy R \& Aquilonius SM (1988). Autoradiographic distribution of $\left.{ }^{3} \mathrm{H}\right]$ acetylcholine binding sites in the cervical spinal cord of man and some other species. Neuroscience Letters, 90: 197202.

11. Bouchenafa O \& Livingston A (1991). The autoradiographic binding of $\left[{ }^{3} \mathrm{H}\right]$ quinuclidinyl benzylate to muscarinic receptors in the spinal cord of the sheep. Journal of Veterinary Pharmacology and Therapeutics, 14: 345-350.

12. Sherriff FE, Henderson Z \& Morrison JF (1991). Further evidence for the absence of a descending cholinergic projection to the spinal cord in the rat. Neuroscience Letters, 128: 52-56.
13. Pedigo NW, Dewey WL \& Harris LS (1975). Determination and characterisation of the antinociceptive activity of intraventricularly administered acetylcholine in mice. Journal of Pharmacology and Experimental Therapeutics, 193: 845-852.

14. Hood DD \& Eisenach JC (1994). Phase I safety assessment of spinal neostigmine in volunteers. Anesthesiology, 81: 26 (Abstract).

15. Hood DD \& Eisenach JC (1994). Side effects and analgesia from spinal neostigmine through a Whitacre needle. Anesthesiology, 81: 27 (Abstract).

16. Lauretti $\mathrm{GL}$, Reis MP, Prado WA \& Klamt JG (1996). Dose-response study of intrathecal morphine versus intrathecal neostigmine, their combination, or placebo for postoperative analgesia in patients undergoing anterior and posterior vaginoplasty. Anesthesia and Analgesia, 82: 1182-1187.

17. Klamt JG, Reis MP, Barbieri Neto J \& Prado WA (1996). Analgesic effect of subarachnoid neostigmine in two patients with cancer pain. Pain, 66: 389-391.

18. Lauretti GL \& Lima IC (1996). The effects of intrathecal neostigmine on somatic and visceral pain: improvement by association with a peripheral anticholinergic. Anesthesia and Analgesia, 82: 617-620.

19. Wood PL (1984). Analgesics: Neurochemical, Behavioural and Clinical Perspectives. Raven Press, New York, 175189.

20. Dubuisson D \& Dennis SG (1977). The formalin test: a quantitative study of the analgesic effects of morphine, meperidine, and brain stimulation in rats and cats. Pain, 4: 161-174.

21. Shibata $M$, Ohkubo $T$, Takahashi H \& Inoki $R$ (1989). Modified formalin test: characteristic biphasic pain response. Pain, 38: 347-352.

22. Zimmermann M (1983). Ethical guidelines for investigation of experimental pain in conscious animals. Pain, 16: 109-110.

23. Yaksh TL \& Rudy TA (1976). Chronic catheterization of the spinal subarachnoid space. Physiology and Behavior, 17: 10311036.

24. Wheeler-Aceto H \& Cowan A (1991). Standardization of the rat paw formalin test for the evaluation of analgesics. Psychopharmacology, 104: 35-44.
25. Malmberg AB \& Yaksh TL (1993). Pharmacology of the spinal action of ketorolac, morphine, ST-91, U50488, and LPIA on the formalin test and an isobolographic analysis of the NSAID interaction. Anesthesiology, 79: 270-281.

26. Wiertelak EP, Furness LE, Watkins LR \& Maier SF (1994). Illness-induced hyperalgesia is mediated by a spinal NMDA-nitric oxide cascade. Brain Research, 664: 9-16.

27. Dickenson AH \& Sullivan AF (1987). Peripheral origins and central modulation of subcutaneous formalin-induced activity of rat dorsal horn neurones. Neuroscience Letters, 83: 207-211.

28. Ryan SM, Watkins LR, Mayer DJ \& Maier SF (1985). Spinal pain suppression mechanisms may differ for phasic and tonic pain. Brain Research, 334: 172-175.

29. Haley JE, Sullivan AF \& Dickenson AH (1990). Evidence for spinal $N$-methyl-Daspartate receptor involvement in prolonged chemical nociception in rat. Brain Research, 518: 218-226.

30. Coderre TJ \& Melzack R (1992). The contribution of excitatory amino acids to central sensitization and persistent nociception after formalin-induced tissue injury. Journal of Neuroscience, 12: 3665-3675.

31. Malmberg AB \& Yaksh TL (1992). Hyperalgesia mediated by spinal glutamate or substance $P$ receptor blocked by spinal cyclooxygenase inhibition. Science, 257: 1276-1279.

32. Ohkubo T, Shibata M, Takahashi H \& Inoki $R$ (1990). Roles of substance $P$ and somatostatin in transmission of nociceptive information induced by formalin in spinal cord. Journal of Pharmacology and Experimental Therapeutics, 252: 1261-1268.

33. Coderre TJ \& Melzack R (1991). Central neural mediators of secondary hyperalgesia following heat injury in rats: neuropeptides and excitatory amino acids. Neuroscience Letters, 131: 71-74.

34. Klamt JG, Slullitel A, Garcia LV \& Prado WA (1997). Postoperative analgesic effect of intrathecal neostigmine and its influence on spinal anaesthesia. Anaesthesia, 52: 547-551. 